\title{
LA DRAMATIZACIÓN DE LA CULTURA. LOS PROCESOS DE CONVERSIÓN EVANGÉLICA AYMARA (CHILE)
}

\author{
THE DRAMATIZATION OF CULTURE: THE PROCESSES OF \\ AYMARA EVANGELICAL CONVERSION (CHILE)
}

\author{
Miguel Mansilla ${ }^{1}$ y Wilson Muñoz $z^{2,3,4}$
}

\begin{abstract}
El movimiento evangélico ha penetrado de manera significativa en las poblaciones aymaras del norte de Chile. El objetivo de este artículo es analizar la relación establecida entre la cultura evangélica y la cultura católica-aymara en Tarapacá, haciendo especial hincapié en las reconfiguraciones socioculturales generadas por los procesos de conversión religiosa en los pentecostales aymaras. A partir del análisis de entrevistas realizadas a evangélicos aymaras de la región de Tarapacá, mostraremos cómo se manifiestan estas reconfiguraciones a nivel personal, grupal y social dentro de esta población.
\end{abstract}

Palabras claves: cultura, conversión, evangélicos, aymaras.

The evangelical movement has penetrated in a significant way in the Aymara population of the north of Chile. The aim of this article is to examine the relation between the Evangelical culture and the Catholic-Aymara culture in the Tarapacá region, emphasizing the sociocultural reconfigurations generated by the processes of religious conversion of the Aymara Pentecostals. From the analysis of interviews made to evangelical Aymara of this region, we will show how these reconfigurations take place at the personal the group and social levels within this population

Key words: Culture, conversion, evangelical, Aymara.

El pentecostalismo arribó al altiplano chileno andino con don Braulio Mamani en 1957, quien se transformó en uno de los misioneros protagonistas de la conversión aymara al pentecostalismo, evangelizando tanto el altiplano chileno como el boliviano (Monast 1972; Rivière 2004; Sepúlveda 1996). Desde aquella época hasta la actualidad la penetración del movimiento evangélico en la población aymara ha sufrido importantes reconfiguraciones y mutaciones, siendo las más destacadas el significativo crecimiento de este movimiento y la creciente diversificación de sus iglesias en la zona.

Durante su primera etapa de desarrollo, este fenómeno llamó la atención de diversos cientistas sociales. En general el movimiento fue concebido inicialmente como una secta, describiendo a los aymaras primeramente como sectarios y solo secundariamente como indígenas, sosteniendo que estos debían renunciar totalmente a sus costumbres aymaras para poder convertirse a la religión evangélica (González 1980, 1981; Guerrero 1981, 1984, 1994; Tudela 1993; Van Kessel 2005). Los investigadores intentaron comprender el impacto que tuvo el pentecostalismo en la cultura aymara usando una lógica de carácter funcionalista, concibiendo la crisis cultural que atravesaba la cultura aymara como una verdadera hecatombe y/o caos cultural, donde el pentecostalismo simplemente encarnaba al agente más extremo de esta inminente destrucción holocáustica. Durante esta primera etapa, los investigadores no observaron mayor diálogo ni sincretismo entre el pentecostalismo y la cultura aymara, haciendo eco de una postura ampliamente extendida en América Latina que concebía a la diversidad y el pluralismo religioso desde la banca de la sospecha y la conspiración (Casilla 1996; Giménez 1996). Por lo tanto, se ubica a la diversidad religiosa en una posición antagónica a la cultura, básicamente porque la cultura era pensada desde una perspectiva estática, orgánica e integradora.

\footnotetext{
Instituto de Estudios Internacionales (INTE), Universidad Arturo Prat. Av. Prat \#2120, Iquique, Chile. mmansilla@unap.cl Universidad de Tarapacá. Av. 18 de septiembre \#2222, Arica, Chile. wilsonsocio@gmail.com

Grup de Investigacions en Sociologia de la Religio (ISOR), Universidad Autónoma de Barcelona, Barcelona, España.

Programa de Doctorado en Antropología social y etnología, Laboratoire d'Anthropologie Sociale, École des Hautes Études en Sciences Sociales (EHESS), París, Francia.
} 
Sin desconocer el aporte que realizaron estas investigaciones, desde aquel entonces hasta la actualidad se han generado importantes reconfiguraciones teóricas y socioculturales. Por un lado, en las ciencias sociales se desarrolló un giro epistemológico hacia perspectivas más comprensivas (hermenéuticas) y que permitían percibir con mayor sensibilidad una serie de situaciones de interacción cultural, entendidas usualmente como conflictivas y dramáticas (Marcus y Fischer 2000). Por otro lado, el movimiento evangélico ha seguido penetrando en las poblaciones aymaras del norte de Chile durante las dos últimas décadas, tanto a nivel rural como urbano. Este crecimiento y desarrollo se ha visto afectado por la imperante cultura aymara-católica característica de la región, la cual también ha generado reconfiguraciones socioculturales en el movimiento evangélico.

Pese a la relevancia de este fenómeno, las especificidades de sus transformaciones recientes no han sido analizadas detalladamente. Este artículo busca contribuir en este ámbito específico. Su objetivo es explorar la relación establecida entre la cultura evangélica y la cultura aymara en Tarapacá, centrándose concretamente en algunas reconfiguraciones socioculturales generadas por los procesos de conversión religiosa en la población evangélica aymara.

Para abordar este problema concebiremos a la cultura como un proceso dinámico que implica tanto la persistencia (estructura) como el cambio (antiestructura) cultural, desplegada muchas veces como un proceso dramático (Turner 1974:32). De esta manera, entregaremos antecedentes que nos permitan explorar a la cultura evangélica aymara en la zona y algunas de sus reconfiguraciones actuales. Esto no solo contribuirá al objetivo específico planteado, sino también nos permitirá cuestionar un doble supuesto: la existencia de una reproducción acrítica de la cultura evangélica y la negación total de la cultura aymara por parte de los creyentes evangélicos.

Metodológicamente hemos optado por utilizar un acercamiento cualitativo, pues esta estrategia es especialmente sensible para relevar información sobre las prácticas socioculturales y su sentido. Se realizaron 26 entrevistas en profundidad a 14 mujeres y 12 hombres de origen aymara, pertenecientes tanto a las zonas rurales como urbanas de la Región de Tarapacá. Todos ellos pertenecían a alguna de las siguientes iglesias evangélicas: Metodista Evangélica
Jesucristo Vive, Iglesia Evangélica Pentecostal (Colchane), Iglesia Evangélica (Cariquima), Evangélica Pentecostal (Camiña), Iglesia Metodista de Chile (Alto Hospicio, Iquique), Iglesia Adventista del Séptimo Día (Camiña), Adventista Séptimo Día (Pozo Almonte), Iglesia Adventista (Alto Hospicio), Iglesia Evangélica Pentecostal (Pozo Almonte) e Iglesia Evangélica Pentecostal (Alto Hospicio). En los templos evangélicos ubicados en las zonas aymaras, como las localidades de Cariquima, Colchane y Camiña, todos los creyentes y pastores son aymaras. Además, en Cariquima y Camiña los cultos y reuniones semanales (de lunes a viernes) se hacen en lengua aymara, mientras que los cultos dominicales se realizan en español, pues asisten jóvenes que no manejan la lengua aymara, quedando reducido su uso a las conversaciones e interacciones de adultos mayores. Por otro lado, en las zonas urbanas observadas no encontramos iglesias con pastores ni creyentes aymaras. Toda la información se codificó con el programa de análisis cualitativo N-Vivo.10, mientras que para el análisis se utilizó la técnica de análisis de discurso (Antaki et al. 2003; Santander 2011).

Finalmente en el texto utilizamos los tres conceptos: evangélicos (para referirnos a pentecostales y protestantes), pentecostales y protestantes, para cuando hacemos la distinción. Pese a que el mayor impacto lo ha tenido el pentecostalismo, no podemos desconocer la importancia que han tenido los protestantes (principalmente la iglesia Adventista) en Camiña y su conexión con los poblados urbanos.

\section{Cultura y Conversión}

La antropología simbólica suele concebir a la cultura como una suerte de urdiembre y estructura de significación socialmente establecida e históricamente heredada, expresada y transmitida en formas simbólicas con las cuales las personas se comunican, perpetuando y desarrollando así sus conocimientos y actitudes frente a la vida (Geertz 2005:20, 88). Esta noción ha sido criticada por no explicar de manera suficiente las transformaciones culturales (Reynoso 1998). Sin bien bajo esta perspectiva clásica se considerarían los fenómenos de cambios socioculturales, el corazón de la crítica apuntaba a los presupuestos teóricos de esta perspectiva, pues no estarían pensados desde y para analizar fenómenos de transformación sociocultural. 
En este artículo utilizaremos una concepción dinámica y procesual de la cultura. Si bien esta perspectiva posee actualmente muchos representantes, aquí rescatamos la propuesta de Turner, especialmente cuando señala que los cambios culturales pueden adquirir dimensiones liminales y dramáticas, lo que permitiría comprender diversos procesos de adaptabilidad social (Turner 1988). Así, consideramos que el conflicto y el dinamismo presente en la interacción entre la cultura aymara y la cultura evangélica puede entenderse de mejor manera si consideremos a la cultura evangélica y aymara pentecostal de manera dinámica, un proceso de continua "producción, actualización y transformación de modelos simbólicos" (Giménez 2005:9). Esta se desplegaría en diversas representaciones, orientaciones y prácticas individuales y sociales, las cuales permitirían reproducir y reestructurar contextos sociales específicos.

Para comprender esta dimensión procesual y dramática de la cultura aymara, antes debemos señalar qué entenderemos por aymara. Los aymara constituyen un grupo étnico culturalmente distinguible, tanto por la población no indígena como también por ellos mismos. La sociedad regional suele identificar a la población indígena como un todo, a través de rasgos como la lengua, la religión, la organización social y la raza (fenotipo). La semejanza de los atributos con los de la población indígena de los países vecinos (Perú y Bolivia) ha permitido la asimilación de este pueblo como un segmento extranjero (Gavilán 2005:82).

Lo primero que debemos dejar en claro es que la presencia de conflicto en la cultura aymara no comenzó con la llegada del pentecostalismo (1958). Es importante recordar que, en cierta forma, la denominada "crisis cultural aymara" ya estaba instalada desde antaño en la zona, siendo asociada sobre todo a los efectos que generaron los acelerados procesos de modernización que caracterizaron a la región durante el siglo XX, así como también la posterior crisis del salitre (González 2002). Sin este antecedente es imposible entender a cabalidad la relación conflictiva que se estableció entre la cultura aymara y el mundo evangélico. En este sentido, si tuviéramos que otorgarle algún rol al movimiento evangélico dentro de este proceso de crisis, simplemente podríamos decir que gatilló un conflicto latente.

El conflicto propiamente religioso se acentuó de manera mucho más palpable en la década de 1980, una vez que los cuestionamientos a la religión católica se hicieran patentes en la sociedad. No obstante, como acabamos de señalar, el problema religioso era el indicio de una crisis cultural mayor, donde se manifestaba la lucha entre la herencia y la autonomía religiosa, entre el monopolio y el pluralismo sacro. Tres hechos se tornaron absolutamente claves en este contexto. Por un lado, durante este periodo se generó una gran migración rural/urbana de los aymaras en la zona. En este nuevo escenario, los templos y redes evangélicas aparecieron en la urbe como verdaderos espacios comunitarios donde se acogía e integraba a los migrantes aymaras, llegando incluso a reemplazar a las familias de origen que habitaban en la zona rural (González 2002); como ocurriera también con los mapuches protestantes y pentecostales (Foerster 1986, 1989). Por otro lado, la Iglesia Católica se percató de la paulatina pérdida de su hegemonía en la zona del altiplano, por lo que comenzó una lucha conflictiva y dramática por recaptar a muchos de los convertidos al pentecostalismo (principalmente). Finalmente, a fines de la década de 1980 se manifiesta explícitamente la reconfiguración de un conflicto interno al movimiento evangélico, donde la principal disputa no enfrentaba ya a evangélicos foráneos y evangélicos aymaras, sino que se trataba más bien de una lucha comunitaria interna entre la población aymara de tradición católica-andina y aquellos convertidos a la religión evangélica (Tudela 1993).

Estos tres hechos sociales se trenzaron hábilmente para formar un haz de relaciones sociales donde el conflicto fue generativo. Consideramos que en este escenario la figura del "drama" resulta clave para interpretar las reconfiguraciones culturales y religiosas que caracterizan a nuestro caso de estudio. Silveira señala que para el caso evangélico, la dramatización "es un teatro en donde los pastores, obreros y fieles, son actores al participar integralmente de los dramas cúlticos que sobrepasan las paredes del templo expandiéndose en la vida cotidiana de cada uno de ellos" (Silveira 2000:91). Como destaca el mismo autor, la dramatización finalmente permite dejar atrás aquella actitud pasiva, reafirmando la posibilidad de que cada actor pueda intervenir realmente en la vida cotidiana, transformándose en "un eficiente instrumento para remover las dificultades concretas de la existencia" (Silveira 2000:58).

No cabe duda de que esta imagen de dramatización ha estado presente en el pentecostalismo y en la 
sociedad aymara. Esto se aprecia de manera ejemplar en la conversión al pentecostalismo de parte de la población aymara, la cual suele realizarse por motivos altamente dramáticos: ante la presencia de una grave enfermedad, la muerte de algún familiar, diversas crisis existenciales, etc. De hecho, nuestra evidencia empírica muestra que ningún entrevistado se inició en el pentecostalismo o regreso a él movido solo por una simple y pura decisión personal. Siempre manifestaron estar constreñidos por circunstancias que evidenciaban claramente la vulnerabilidad humana, haciendo patente con ello la dimensión dramática de uno de los momentos más significativos dentro de la cultura pentecostal.

Consideramos que la conversión puede ser entendida como una movilidad religiosa dramática que implica un cambio radical en la historia de vida del converso (Garma 2004), pues implica una transformación radical de su identidad y orientación vital. Este proceso supone el tránsito de un universo discursivo a otro (Prat 1997), donde se construyen relatos que ensombrecen el cuadro de los tiempos precedentes, justificando así la nueva adhesión religiosa (Hervieu-Léger 2004). Lo radical o rupturista en este proceso es la intencionalidad y el proceso electivo del actor social, más allá de si prácticas son ejercidas bajo presión, manipulación o si se ven empujados a ella. Es en la misma escenificación pragmática de sus acciones donde se manifiesta esta forma (muchas veces soterrada) de disrupción.

La conversión es un proceso dramático en sí mismo que aumenta o disminuye según los contextos históricos. En nuestro caso de estudio, muy pocas personas pueden decir que se han convertido al pentecostalismo o al protestantismo porque simplemente les "atraía" el movimiento. Una conversión significa más bien el último paso dado luego de haber vivido algunas experiencias previas especialmente dramáticas por la persona, como la enfermedad, el alcoholismo, el desempleo, la muerte o la violencia intrafamiliar, entre otras. Así, podemos admitir que la conversión está íntimamente relacionada con la crisis. Cuando el proceso de conversión se enfría, el convertido inicia un proceso de redefinición y ponderación de la renuncia, y la asunción de las nuevas creencias y prácticas religiosas. Esto se manifiesta de manera diferenciada entre hombres, mujeres y jóvenes aymaras, además de variar según el entorno urbano o rural.
Pese a su radicalidad, la conversión es siempre un proceso social relativo. Por más que el actor quiera o desee negar su pasado, socialización o herencia cultural interiorizada, es difícil lograrlo completamente. Nunca será un proceso de total vaciamiento cultural, sino siempre personal y socialmente situado, en coherencia con la cultura que la sustenta. Si bien esto parece algo relativamente evidente dentro del ámbito de las ciencias sociales, los investigadores clásicos del pentecostalismo aymara en el norte de Chile han tendido a describir el fenómeno de la conversión como un fenómeno que implica una especie de desaparición de la identidad (católica-andina) anterior, olvidando que la identidad normalmente "permanece en forma latente o dormida y se hace visible cuando las circunstancias lo demanden" (Fortuny y Loret 1998:150). Así, hemos olvidado que si bien un aymara, cuando se convierte en evangélico, podrá esforzarse en no ser aymara, difícilmente podrá desprenderse absolutamente de su cultura, la cual normalmente ha sido ya internalizada en gran medida. Además, esa especie de negación de la cultura que se desarrolla en el seno del movimiento evangélico, luego de ser analizada empíricamente, emerge como una forma específica de vivenciar la cultura aymara ante la presencia de una crisis cultural y la llegada del pentecostalismo. Consideramos que este es el punto más importante a la hora de analizar la falsa dicotomía entre cultura aymara y cultura evangélica en el norte de Chile esculpida por los estudios clásicos. Las diversas formas de apropiación y reapropiación que los aymaras realizan de la cultura evangélica, y viceversa, forman parte también de esta cultura aymara que constantemente se ve refundada y reactualizada en nuestros días.

Un ejemplo clave donde se manifiesta esta imbricación es en la reinterpretación cosmológica que realizan los pentecostales convertidos de su tradición aymara. En términos muy generales, la cosmología aymara distingue la existencia de tres espacios en el universo: alaxpacha, akapacha y manqhapacha. El primero es el mundo de arriba, el cielo, un mundo de luz imperceptible a los sentidos. Para los pentecostales el alaxpacha es interpretado como el cielo, la morada de Dios y de los ángeles. Es un espacio que posee poder sobre la tierra. Por su parte el akapacha es el mundo de la tierra, la morada de los seres humanos, animales y vegetales. Para los pentecostales es la morada de los seres humanos, el mundo del trabajo y del sufrimiento. 
Normalmente se distinguen dos tipos de trabajo: el material y el espiritual, siendo el más importante el trabajo espiritual, el cual está relacionado con la predicación, la oración y el culto. Por último, el manqhapacha es el mundo de abajo o el subsuelo, donde existen fuerzas poderosas e incontrolables. Para los pentecostales este espacio es el infierno, la morada del diablo y sus demonios. Es un mundo incontrolable para aquellos que no tienen el Espíritu Santo. Todos los convertidos y bautizados por el Espíritu Santo tienen poder sobre él, el cual se manifiesta normalmente de manera ritual. Por ejemplo, mientras que la tradición aymara-católica puede señalar que el diablo y sus demonios producen las enfermedades, las malas cosechas o la muerte de los animales; los pentecostales manifiestan un poder para exorcizar el mal y sus consecuencias luego de su conversión. Poder simbólico, que no solo está en el pastor, sino en cada creyente.

\section{Crisis y Recursos Simbólico-Rituales}

La nueva religión evangélica quiso constituirse en una especie de re-fundacionalismo cultural, operando de manera predilecta por el fenómeno de la conversión. Ello implica que a través de la conversión la religión es situada y la cultura se vuelve dinámica. Así, la religión es situada culturalmente, proporcionado además "los marcos de acción y guía al individuo para la elección de cursos de acción específica" (Amparán 1999:45).

Este re-fundacionalismo y dinamización cultural que opera durante el proceso de conversión, se escenifica y reproduce de manera especial en todas las ritualidades cúlticas que caracterizan a la tradición pentecostal, las cuales luego suelen ser producidas, reproducidas y aplicadas en la esfera de la cotidianeidad. En este punto recordamos que Turner destaca que todo proceso de conversión implica procesos rituales muy significativos tanto para el actor social directamente involucrado como para el grupo en general (Turner 1974, 1988). En el rito, la conversión puede adquirir incluso cierto nivel de politización con la finalidad de construir la diferencia y superioridad del grupo actual con relación a la anterior. De esta forma se podrá mostrar una mayor eficacia de los ritos o de las plegarias.

Es por ello que los procesos dramáticos devienen en espectacularidad, acompañados de una diversificación de ritualidades, sobre todo las aflictivas. $\mathrm{Y}$ es en estas ritualidades donde el pentecostalismo tiene más efectividad. Porque los cultos se suelen constituir en tiempos catárticos, donde se hace manifiesta "la formulación de propuestas simbólico-rituales que ofertan la salida al conflicto social y la afirmación operacional de las vías cohesivas rituales y simbólicas que superan el conflicto social tanto en la conversión como en la restauración" (Melgar 2001:16). Es por ello que diversos autores han destacado la importancia de la dimensión cúltico-ritual dentro del pentecostalismo a nivel global (Anderson 2007; Moulian 2004, 2012; Muñoz 2011; Robbins 2004, 2009).

Debemos recordar que a nivel latinoamericano el pentecostalismo ha sido una religión de los pobres, indígenas, campesinos, hombres y mujeres populares. $\mathrm{Su}$ desarrollo ha sido el correlato (muchas veces indeseado) de grandes y acelerados procesos de modernización que han traído aparejados importantes procesos de reconfiguración sociocultural (Míguez 1998, 2000). En este escenario, diversos autores han señalado que el crecimiento y el éxito del pentecostalismo latinoamericano se ha debido a que este movimiento ha ofrecido y ofrece maneras alternativas y efectivas para comprender y superar las crisis sociales, culturales y personales, por las cuales atravesarían especialmente las capas sociales menos favorecidas de nuestras sociedades (Bastian 1997; D’Espinay 2009; Mansilla 2009; Orellana 2008).

Es en este contexto que se ha señalado que el movimiento evangélico es una religión de la crisis, pues "ofrece sentido de vida; crea lazos de identidad individual y social; brinda soluciones a problemas inmediatos; crea redes de instituciones sociales; posibilita procesos de movilidad social ascendente; y permite percibir nuevas formas de participación política en el futuro" (Pereira 1996:8). Pero si bien el pentecostalismo puede ofrecer una particular cosmología cristiana que permite explicar estos procesos de transformación y crisis a nivel societal, parecería ser que el pentecostalismo se muestra más eficaz en situaciones que pueden enfrentarse individualmente, donde son "los mecanismos de fortalecimiento psíquico a través de la consolidación de la autoestima y las redes solidarias" los que finalmente resultan efectivos para superar las crisis personales (biográficas) coyunturales (Miguez 2001:84). En otras palabras, y de manera algo más concreta, la capacidad resolutiva de los evangélicos no se despliega tanto en el plano social, de hecho suelen ser criticados muchas veces por cierta pasividad en este orden (Parker y Fediavoka 2009), sino más 
bien en el ámbito de transformación personal que generan la incorporación de una nueva concepción de la vida.

Normalmente esta concepción e interpretación de la vida suele tener ribetes dramáticos. De hecho, nuestro análisis empírico muestra que los aymaras se convierten al pentecostalismo por las mismas razones que otros chilenos u otros indígenas latinoamericanos. La diferencia no reside en la demanda ni en la oferta religiosa (según las teorías de la rational choice) ni en un plano netamente funcional, sino en los códigos culturales locales que ofrece la tradición aymara y que son reinterpretados y utilizados pragmáticamente por los pentecostales. Lo característico de los evangélicos aymara es el uso de recursos simbólicos y rituales específicos para interpretar las crisis personales y sociales, y expresarlas dramáticamente.

En términos más concretos, las crisis, las rupturas y los dramas suelen ser comprendidos y enfatizados a través del uso simbólico de metáforas particulares, las cuales brindan al creyente y al converso aymara una serie de símbolos con determinados significados que el afectado puede recepcionar activamente y llenar de contenido. Las metáforas evangélicas aymaras que nos transmiten visiones de vida marcadas por las figuras de la crisis y el drama, podemos encontrarlas de manera sobreabundante en los diversos testimonios, prédicas y cantos que se despliegan en las representaciones cúlticas que caracterizan a este movimiento.

Luego de realizar nuestro análisis empírico, pudimos apreciar que las metáforas más utilizadas por los evangélicos aymaras remiten a imágenes climáticas, geográficas, marinas y fáunicas. Algunos ejemplos concretos de ellas se pueden apreciar en las siguientes frases utilizadas cotidianamente durante la realización de actividades cúlticas: (1) metáforas climáticas: "rodeados de nubes sin ver el sol", "sombras que no permiten la calidez", "oscuridad que no permiten caminar", etc.; (2) metáforas geográficas: "pasar por el desierto", "andar por caminos angostos", "caminar por cerros encumbrados"; (3) metáforas del pescador: "una frágil barca enfrentando terribles marejadas"; "un barco sin timón", "un pescador, que a pesar de su esfuerzo, no ha pescado ningún pez"; (4) metáforas fáunicas: "una pequeña ave en las fauces de un felino", "una oveja herida", "un animal neonato abandonado", etc. Todas estas metáforas se alimentan del imaginario bíblico y son usadas por el cristianismo. Sin embargo, lo que es característico del pentecostalismo es su utilización para enfatizar una visión dramática de la vida. Además, estas imágenes parecieran acomodarse de buena manera al paisaje andino, donde el desierto, la altitud, la extrema oscilación térmica y los escarpados caminos, conforman un entorno duro y agreste que encuentra eco en estas metáforas, siendo reapropiadas con pertinencia cultural por los aymaras evangélicos.

A través de las metáforas, los individuos suelen seleccionar, enfatizar y suprimir rasgos de las relaciones sociales en relación con la naturaleza (Turner 1974:31). Y en todas las experiencias que suelen rodear al proceso de conversión religiosa relatadas por los evangélicos aymaras, aparece en una primera instancia un individuo inerme y abandonado frente a una naturaleza (sociedad) abúlica, la cual se resuelve cuando aparece Jesús como un redentor personal. Y aunque el problema concreto que posee el individuo no se resuelve necesaria ni obligatoriamente, al menos se siente capacitado para salir de esta situación crítica. Aunque, paradójicamente, jamás se logre salir enteramente de esta situación en vida, entre otras cosas por la comprensión trágica y dramática que se posee de la misma, la cual será revertida solo cuando llegue el fin de los tiempos.

Esta concepción dramática de la vida expresada en diversas metáforas, finalmente le otorga a los evangélicos los símbolos necesarios para expresar los problemas y pesares que los aquejan cotidianamente. De alguna forma, así los evangélicos aymaras han logrado adaptarse a las nuevas demandas y necesidades de los feligreses, logrando mantener su membresía (pese a que su crecimiento ha disminuido en los últimos años).

Pero más allá del uso de recursos metafóricos que ofrece la comunidad pentecostal para dotar de sentido a una existencia teñida de crisis personales y sociales, en el seno del movimiento se despliegan otros recursos rituales que permiten enrolar de manera sostenida a los neófitos e integrantes de la comunidad a la iglesia, por un lado, y entregar diversas herramientas prácticas para replantear y conllevar las crisis personales y sociales que afectan a sus integrantes, por otro lado. De esta manera, los diversos rituales ofrecen verdaderas cadenas de interacción que les permiten seguir reproduciéndose a sí mismos de manera dramática, al mismo tiempo que ofrecen una energía emocional que emerge 
socialmente en estas ritualidades (Robbins 2009). En este escenario el rol de la comunidad es clave.

Los autores que investigaron inicialmente al pentecostalismo aymara resaltaron su capacidad de acción comunitaria conjunta sobre los feligreses, subrayando que se trataba de uno de los elementos más significativos del pentecostalismo (González 1981; Guerrero 1984) y protestantismo aymara (Tudela 1993). En Chile se evidenció una crisis del sueño igualitarista de las comunidades pentecostales en la década de los sesenta (Mansilla 2014), manifestándose posteriormente en una crisis de la propuesta de comunidad pentecostal en el mundo urbano, donde las personas toleraban cada vez menos la excesiva exigencia de la comunidad religiosa. No obstante, justo cuando esta propuesta de comunidad entra en crisis en la urbe, al mismo tiempo comienza a desarrollarse vigorosamente en el mundo aymara (1957) en un contexto de crisis cultural.

Esta forma de operar comunitaria posee un correlato concreto en una serie de prácticas rituales que permiten integrar a los actores a la comunidad evangélica aymara, a la vez que le ofrecen mecanismos que permitan replantear y/o sobrellevar las crisis personales y sociales que suelen aquejarlos. A partir del análisis empírico hemos podido identificar tres grandes mecanismos que operan de manera ritualizada y suelen ser efectivos ante estas situaciones.

La primera forma utilizada por parte de los evangélicos para resolver estos problemas son la acogida y el acompañamiento personal y social que se le ofrece a todo neófito. La acogida está asociada al contacto afectivo que la comunidad le otorga al visitante. La comunidad considera que el primer contacto que establecen los hermanos cristianos con la persona que visita recientemente un templo es un asunto extremadamente importante, pues se trata de la primera instancia donde el neófito toma contacto con esta nueva comunidad. El afecto, las muestras de cariño, abrazos y el ofrecimiento de oración que normalmente son desplegados en este primer encuentro, suelen hacer manifiesto el afecto e interés por la persona recién llegada. Pero además, se debe hacer explícita la muestra de desinterés para que la persona que realiza su primera visita no se sienta utilizada, y experimente que existe un interés genuino por su persona y sus problemas. Es decir, que la ayuda ofrecida no se haga solo por el interés en la conversión, el bautismo o un posterior aporte económico que deba realizarse a la iglesia (como ocurre en algunas congregaciones). Este proceso requiere de un tiempo determinado y de formas adecuadas de comunicación que hacen posible el establecimiento de relaciones afectivas y relativamente discretas, basadas sobre todo en la confianza interpersonal cultivada en el seno de la comunidad.

Es importante mencionar aquí un factor de género, pues son las mujeres quienes son concebidas como las más adecuadas y propicias para establecer estas relaciones. De hecho, las iglesias son visitadas fundamental y primariamente por mujeres. Son ellas quienes finalmente buscan más ayuda y que también la ofrecen en los diversos templos que pueblan los Andes. Finalmente, existen diversos aspectos que la religión evangélica define y legitima como femeninos, como por ejemplo: hablar, buscar, aceptar y brindar ayuda, llorar, entre muchos otros; y es por ello que suelen ser las mujeres quienes operan como personas que poseen una sensibilidad, conocimiento y prácticas distintivas que les permiten ser las más adecuadas (expertas) para otorgar esta ayuda simbólico-ritual de compensación emocional. Una situación que está en clara concordancia con la tradición aymara, donde el rol de la mujer suele tener estas asignaciones.

Una segunda manifestación concreta de este acompañamiento personal y social, emerge cuando alguien de la comunidad se enferma o pasa por problemas graves de diversa índole. En este escenario, la comunidad suele realizar un trabajo "de apoyo para activar y movilizar recursos, capacidades, potencialidades de las personas y de su entorno" (Pérez 2004:11). Este acompañamiento es característico dentro de la tradición evangélica y vienen practicándolo desde sus orígenes. Se trata de una labor que normalmente suelen llevar a cabo los líderes de las iglesias y también las mujeres, aunque pueden desarrollarlo todos los feligreses. Es un "trabajo de relación personal continuada, relativamente duradera, de comprender a las personas para contribuir a que ellas mismas entiendan y empiecen a dominar su situación y las claves de sus dificultades" (Pérez 2004:11). Esta labor de acompañamiento permitiría que la compensación (religiosa-ritual) sea capaz tanto de manipular como de restaurar las crisis que afectan al individuo y/o la comunidad. En términos más concretos implica llevar a cabo prácticas rituales como orar (oraciones cúlticas, intercesoras, etc.), realizar ayunos, ungimiento con aceite, practicar 
la imposición de manos (taumaturgia). Tanto este acompañamiento personal y social, como la dimensión ritual que lo acompaña, posee ciertas analogías con la tradición aymara.

Durante el desarrollo de cada una de estas ritualidades, las personas suelen percibir el interés que poseen los integrantes de la comunidad hacia su persona y sus problemas, los que generalmente nunca se solucionan del todo, pero al menos, gracias a ritualidades como las recién mencionadas donde el acompañamiento es clave, pueden sobrellevar de una manera más razonable, tanto a nivel cognitivo como emocional y social. La persona ya no se siente sola y sabe que sus problemas pueden ser comprendidos y sobrellevados por otros, pues finalmente lo más importante para la comunidad es que esta persona también pueda ayudar a otros a conllevar sus problemas a través de la práctica de rituales.

Finalmente también es importante recordar que cuando algún congregante decide irse de la iglesia, la comunidad utiliza estrategias específicas para convencer y disuadir al creyente de lo contrario. En términos rituales, se trataría de una especie de fase potencialmente reparadora generada por el alejamiento del creyente. Esto sucede de manera especial en el pentecostalismo, aunque también en el protestantismo, pues se trata de tradiciones cristianas caracterizadas por la práctica del proselitismo; mientras que la Iglesia Católica, al menos actualmente, no posee mayores estrategias o mecanismos para disuadir a sus creyentes para que retornen al redil. Al parecer, esta especie de falencia ritual del catolicismo institucional (a diferencia del catolicismo popular), estaría relacionada con el sentimiento de abandono y desvalorización por el lado de la nueva religión. De igual forma, cuando algún creyente se va de las iglesias pentecostales o protestantes, estas comunidades elaboran una serie de acciones de desagravios, activando mecanismos de ajustes y reparación. Por ejemplo, las constantes visitas que se realizan a la casa del rebelde converso para poder reintegrarlo finalmente al redil. Aquí la expresión redil y sus individualidades fáunicas, adquieren un ribete real, que los aymaras logran comprender ¿Cuáles son los riesgos de un ovino que se aleja del redil? ¿Cómo logrará enfrentar la sociedad interpretada como noches, desierto o quebrada rodeados de caninos? Por ello la búsqueda, la salida y el encuentro con el descarriado son rituales llenos de simbolismos. Este último mecanismo ritual quizás sea el punto de mayor diferencia con la tradición aymara, pues no existen prácticas análogas con este nivel de especificación ni intensidad.

En general, consideramos que dado que esta serie de prácticas de acogida, acompañamiento y convencimiento, suelen ser ejecutadas de manera ritualizada y reiterada en el contexto aymara pentecostal, finalmente permiten que se establezca una estructura de interacción comunicativa ritual duradera en el tiempo. Quizás esta sea una de las características más distintivas a nivel organizacional del pentecostalismo (Robbins 2004, 2009). La presencia de verdaderas cadenas de interacción ritual (Collins 2004), permiten establecer vínculos específicos entre los integrantes de la comunidad y los neófitos, a través del mantenimiento de una efervescencia emotiva que suele recrearse día a día en los encuentros. Finalmente, esta energía emotiva suele operar como un factor simbólico de coordinación que seduce y motiva a los participantes. En este punto, lo distintivo del evangélico aymara serían los códigos culturales específicos que se utilizan para llevar a cabo a estos procesos simbólicos y rituales. En ese sentido, los evangélicos, más allá de las aparentes oposiciones con la tradición aymara, parecieran haber visto en ella un terreno simbólico y ritual extremadamente rico, el cual es reinterpretado y reutilizado de manera contextual por sus conversos. De esta forma, la efervescente tradición ritual del pentecostalismo se ve nutrida por la rica tradición ritual aymara. De ahí su importancia para toda la comunidad de evangélicos aymaras.

\section{Consideraciones Finales}

A lo largo de este artículo hemos tratado de poner en evidencia algunas reconfiguraciones culturales que se han producido en el mundo evangélico aymara en el norte de Chile, poniendo especial atención en el fenómeno de la conversión religiosa. Hemos intentado poner en cuestión aquellos supuestos funcionalistas presentes en diversos estudios que tienden a dibujar a la cultura aymara y evangélica como mundos totalmente contrapuestos y antagónicos, donde tanto los indígenas como los creyentes suelen ser conceptualizados como actores pasivos, y donde los conflictos y las crisis son vistos como fenómenos meramente negativos y no productivos socialmente.

Por un lado, hemos mostrado que la conversión que realizan los aymaras a la religión evangélica 
normalmente es un proceso relacionado con las crisis personales, grupales y sociales que estos experimentan. Según los testimonios analizados, una conversión suele ser el último paso luego de haber vivido experiencias previas especialmente dramáticas, como la enfermedad, el alcoholismo, el desempleo, la muerte o la violencia intrafamiliar. Así, podemos admitir que la conversión está íntimamente relacionada con la crisis. En este escenario, las diversas formas de apropiación y reapropiación que los aymaras realizan de la cultura evangélica, forman parte de esta tradición aymara que constantemente se ve refundada y reactualizada. Incluso esa especie de negación de la cultura que se desarrolla en el seno del movimiento evangélico, emerge como una forma específica de vivenciarla. Esto es especialmente importante para derrocar la falsa dicotomía esculpida por los estudios clásicos entre cultura aymara y evangélica.

Por otro lado, debemos comprender que la nueva religión evangélica vino a constituirse en una especie de re-fundacionalismo cultural (aunque nunca total) en el contexto aymara, operando de manera predilecta a través del fenómeno de la conversión. Esta re-dinamización cultural se escenifica y reproduce de manera especial en las ritualidades cúlticas que caracterizan a la tradición pentecostal, las cuales luego suelen ser producidas, reproducidas y aplicadas localmente. Es en estas ritualidades donde el pentecostalismo se torna más efectivo a la hora de pensar, comprender y resolver los problemas y crisis personales. En este escenario, los evangélicos ofrecen una serie de metáforas plurales que brindan al creyente y al converso aymara diversos símbolos que el afectado puede recepcionar activamente y llenar de contenido. Además, en el seno del movimiento se despliegan múltiples recursos rituales que permiten enrolar de manera sostenida a los neófitos y entregar herramientas prácticas para replantear y conllevar sus crisis. Se trata de una serie de prácticas de acogida, acompañamiento y convencimiento, ejecutadas de manera ritualizada y reiterada en el contexto aymara pentecostal, y que finalmente permiten que se establezcan una estructura de interacción comunicativa ritual duradera en el tiempo. En general, estas prácticas rituales que pueden ser fácilmente identificables como parte de la tradición pentecostal y suelen poseer claras analogías con la tradición aymara. Esto permite establecer vínculos específicos entre los integrantes de la comunidad y los neófitos a través del mantenimiento de determinada efervescencia emotiva que suele recrearse en cada encuentro ritual. Finalmente, esta energía emotiva suele operar como un factor simbólico de coordinación que seduce y motiva de manera especial a los participantes, lo que lo convierte en un factor relevante para la comunidad aymara pentecostal.

Agradecimientos: Este artículo es resultado del proyecto FONDECYT No 3120162 (CONICYTChile). El coautor es becario CONICYT (programa Becas Chile). De igual modo agradecemos los comentarios y sugerencias de los evaluadores que permitieron mejorar este artículo.

\section{Referencias Citadas}

Anderson, A. 2007 [2004]. El Pentecostalismo. El Cristianismo Carismático Global. Akal, Madrid.

Antaki, Ch., M. Billing, D. Edward y J. Potter 2003. El análisis del discurso implica analizar: seis atajos analíticos. Atenea Digital 3:1-22.

Bastian, J. 1997. La Mutación Religiosa de América Latina. Para una Sociología del Cambio Social en la Modernidad Periférica. Fondo de Cultura Económica, Ciudad de México.

Casillas, R. 1996. La pluralidad religiosa en México: descubriendo horizontes. En Identidades Religiosas y Sociales en México, coordinado por G. Giménez, pp. 67-102. Universidad Autónoma de México, Ciudad de México.

Collins, R. 2004. Interaction Ritual Chains. University Press, Princeton.

D’Espinay, C. 2009 [1968]. El Refugio de las Masas: Estudio Sociológico del Protestantismo Chileno. Universidad de Santiago de Chile - Centro Evangélico de Estudios Pentecostales, Santiago.

Foerster, R. 1986. La misión anglicana, primera iglesia protestante entre los mapuches. Nütram 3:14-28.

Foerster, R. 1989. Identidad y pentecostalismo indígena en Chile. Creces 6:12-18.

Foerster, R. 1993. Introducción a la Religiosidad Mapuche. Editorial Universitaria, Santiago.

Foerster, R. 2007. ¿Último longko o cacique malonero? Contraimaginarios de Manuel Olasxoaga y Ambrosio Payllalef. En Mapuches y Anglicanos. Vestigios Fotográficos de la Misión Araucana de Kepe, 1896-1908, coordinado por A. Menard y J. Pavez, pp. 107-114. Ocho Editores, Santiago.

Fortuny, P. y L. De Mola 1998. Lo religioso, núcleo de identidad en los conversos. En Sectas o Iglesias. Viejos o Nuevos Movimientos 
Religiosos, compilado por E. Mansferrer, pp. 123-154. Editorial Plaza y Valdés, Ciudad de México.

Garma, C. 2004. Buscando el Espíritu. Pentecostalismo en Iztapalapa y la Ciudad de México. Universidad Autonóma de México - Plaza Valdés, Ciudad de México.

Gavilán, V. 2005. Identidades étnicas en Tarapacá a inicios del siglo XXI. Revista de Dialectología y Tradiciones Populares 60:77-102.

González, S. 1990. El Aymara de la Provincia de Iquique-Chile y la Educación Nacional. Taller de Estudios Regionales, Iquique.

González, S. 2002. Chilenizando a Tunupa. La Escuela Pública en el Tarapacá Andino 1880-1990. Dirección de Bibliotecas Archivos y Museos - Centro Barros Arana, Santiago.

González, Y. 1980. La familia aymara: una estructura desintegrada y dominada. Cuaderno de Investigación Social 3:34-38.

González, Y. 1981. La nuclearización de la estructura familística autóctona y el proceso de dominación interna. Cuaderno de Investigación Social 4:24-29.

Geertz, C. 2005 [1973]. La Interpretación de las Culturas. Gedisa, Barcelona.

Giménez, G. 1996. El debate actual sobre modernidad y religión. En Identidades Religiosas y Sociales en México, coordinado por G. Giménez, pp. 1-22. Universidad Autónoma de México, Ciudad de México.

Giménez, G. 2005. La cultura como identidad y la identidad como cultura. Actas del III Encuentro Internacional de Promotores y Gestores Culturales. Red Nacional de Información Cultural, Jalisco.

Guerrero, B. 1994. A Dios Rogando... Los Pentecostales en la Sociedad Aymara del Norte Grande de Chile. Free University Press, Amsterdam.

Guerrero, B. 2005. De Indio a Hermano. Pentecostalismo Indígena en América Latina. Ediciones Campvs, Iquique.

Hervieu-Léger, D. 2004. El Peregrino y el Convertido. La Religión en Movimiento. El Helénico, Ciudad de México.

Mansilla, M. 2009. La Cruz y la Esperanza. La Cultura del Pentecostalismo Chileno en la Primera Mitad del Siglo XX. Ediciones Universidad Bolivariana, Santiago.

Marcus, G. y M. Fisher 2000 [1986]. La Antropología como Crítica Cultural. Un Momento Experimental en las Ciencias Humanas. Amorrortu, Buenos Aires.

Melgar, R. 2001. El universo simbólico del ritual del pensamiento de Víctor Turner. Estudios Antropología 7:7-21.

Míguez, D. 1998 ¿Qué puede agregarse a los clásicos?: Buscando nuevos horizontes a los estudios sobre el Pentecostalismo Latinoamericano. Newsletter de la Asociación de Cientistas Sociales de la Religión en el Mercosur 6.

Míguez, D. 2000. Conversiones religiosas, conversiones seculares. Comparando las estrategias de transformación de identidad en programas de minoridad e iglesias pentecostales. Ciências Sociais e Religião 2:31-62.

Monast, J. 1972. Los Indios Aymaras. Carlos Lohlé, Buenos Aires.

Moulian, R. 2004. De la reflexividad social a las mediaciones rituales: Mutaciones, convergencias y paradojas en el lepün y el culto pentecostal. Revista Austral de Ciencias Sociales 8:29-50.
Moulian, R. 2005. Mutaciones, convergencias y paradojas en el lepún y el culto pentecostal. La contraparte de la reflexibilidad ritual. Revista de Estudios para el Desarrollo Social de la Comunicación 2:113-134.

Moulian, R. 2012. Metamorfosis Ritual. Desde el Nguillatún al Culto Pentecostal. Teoría, Historia y Etnografía del Cambio Ritual en Comunidades Mapuche Huilliche. Kultrún, Valdivia.

Muñoz, W. 2011. El olvido del rito. Notas críticas sobre los estudios del pentecostalismo latinoamericano. Perifèria 15:1-28.

Muñoz, W. y M. Mansilla 2015. Conflacionismo epistemológico: Los estudios sobre el pentecostalismo aymara en Chile (19751998). Cinta de Moebio 52:1-16.

Orellana, L. 2008. El Fuego y la Nieve. Historia del Movimiento Pentecostal en Chile 1909-1932. Centro Evangélico de Estudios Pentecostales, Concepción.

Parker, C. y E. Fediakova 2009. Evangélicos en Chile Democrático (1990-2008): radiografía al centésimo aniversario. Cultura y Religión 3:48-75.

Pereira, M. 1996. El pentecostalismo: nuevas formas de organización religiosa en los sectores populares. Origen, evolución y funciones en la sociedad colombiana. 1960-1995. Historia Crítica 12:43-68.

Pérez. B. 2004. El acompañamiento social como herramienta de lucha contra la exclusión. Documentación Social 135:89-108.

Prat, J. 1997. El Estigma del Extraño. Un Ensayo Antropológico sobre las Sectas Religiosas. Ariel, Barcelona.

Reynoso, C. 1998. El Surgimiento de la Antropología Posmoderna. Gedisa, Buenos Aires.

Rivière, G. 2004. Bolivia: el pentecostalismo en la sociedad aimara del Altiplano. En Gracias a Dios y a los Achachilas. Ensayos de Sociología de la Religión en los Andes, compilado por A. Spedding, pp. 259-294. Instituto Superior Ecuménico Andino de Teología - Plural Editores, La Paz.

Robbins, J. 2004. The globalization of pentecostal and charismatic christianity. Annual Review of Anthropology 33:117-143.

Robbins, J. 2009. Pentecostal Networks and the Spirit of Globalization. On the Social Productivity of Ritual Forms. Social Analysis 53:55-66.

Santander, P. 2011. Por qué y cómo hacer análisis de discurso. Cinta de Moebio 41:207-224.

Sepúlveda, J. 1996. The Andes. The Encounter of Two Forms of Christianity with Andean Religion. Gospel y Cultures Pamphlets - WCC Publications, Geneva.

Silveira, L. 2000. Teatro, Templo y Mercado. Comunicación y Marketing de los Nuevos Pentecostales en América Latina. Abya Yala, Quito.

Tudela, P. 1993. Cambio religioso y revitalización de la comunidad entre los aymaras de Arica 1960- 1990. Nutram 33:15-48.

Turner, V. 1974. Dramas, Fields, and Metaphors. Cornell University Press, Ithaca.

Turner, V. 1988 [1966]. El Proceso Ritual. Taurus, Madrid.

Van Kessel, J. 1980. Holocausto al Progreso. Los Aymaras de Tarapacá. Centro de Estudios y Documentación Latinoamericanos, Ámsterdam. 